\title{
Packet Warriors: An Academic Mobile Action Game for Promoting OSI Model Concepts to Learners
}

\author{
https://doi.org/10.3991/ijim.v13i06.10469
}

\author{
Thanakorn Uiphanit, Pattarasinee Bhattarakosol( $\left.{ }^{(}\right)$, \\ Kwanrat Suanpong, Sompoch Iamsupasit \\ Chulalongkorn University, Bangkok, Thailand \\ pattarasinee.b@chula.ac.th
}

\begin{abstract}
This research aims to develop a game to teach the theoretical concepts of the OSI reference model to students who must learn data communication and networking as a compulsory or an elective subject. The survey was administered to most students at Suan Sunandha Rajabhat University by a questionnaire to assess a suitable game for students of this generation. The result showed that action games are the most popular game for them. Then, a script of the OSI reference model was drawn based on the theoretical contents and the software design and implementation were performed. After finishing this development process, 19 third-year undergraduate students majoring in information sciences at Suan Sunandha Rajabhat University tested this system. The evaluation process was performed using pretest and posttest data analyzed by a paired samples t-test at a $95 \%$ confidence level. The result of this study shows that the action game 'Packet Warrior' is an efficient tool to help students improve their learning capabilities via fun and good relationships with friends.
\end{abstract}

Keywords-Educational games, OSI model, computer network, action game

\section{$1 \quad$ Introduction}

Computer networking is the most important subject for undergraduate students majoring in Information and Communication Technology (ICT). Additionally, it is also an important elective subject for all non-ICT students in every university. Due to continual evolution in computer network technology, both hardware and software have been changed so much altered. These changes led to the globalization of the Internet, and information has spread omnidirectionally through the Internet. Thus, any individuals with mobile devices with Internet access can browse information anywhere anytime as needed. Therefore, knowledge of computer net-working is crucial in this digital era.

Although the fundamental concepts in computer networking are vital, the context of these fundamental concepts is also dependent on students' academic areas. Nevertheless, one major topic that every student must know about the communication network is the networks reference model, namely, the open systems interconnection (OSI) reference model. This reference model is the basis of all communication func- 
tions, such as communication protocols. Although the OSI reference model is important, not many students are excited to study this topic.

According to [17], a game-based learning module was implemented to stimulate students' interest and understanding in the OSI reference model. The result of this game-based learning method indicated that students understood the subject's content much better than they did via traditional teaching methods such as lectures. However, in the theoretical part, the lecture is still necessary because it is the simplest way to interact with students. Nevertheless, this method impedes some students' understanding because they perceive the theoretical contents of computer networking as complicated, boring, and difficult to learn [17]. Consequently, many students do not pay much attention to theoretical knowledge because they misunderstand that this knowledges is not necessary for application in real life. Nevertheless, whenever a new network technology needs to be implemented and sets the standard, the OSI reference model is necessary ([6],[7],[18]).

Based on the problem defined above, three professional persons in the computer network are interviewed: one from the academic area and two from an information technology training and consulting services company. The outcomes from these interviews are various opinions related to the focusing problem and their suggested solutions.

Currently, many teaching techniques and various materials are available over the Internet, especially on youtube.com, such as the short film "Warriors of the net" (http://www.warriorsofthe.net/)[8], the packet traces simulation software[8], the physical activity game "Tablets of Stone"[3], the embedded hardware device for learning computer network protocols "Serious toys 2"[5], and a casual digital game called "Packet Attack"[8]. Although there are many alternatives, there is little evidences to indicate that the learning problems of students regarding the theoretical contents of computer networks are resolved. Nonetheless, a study in educational games by [6] has determined that students are able to interact and immerse them-selves in the lesson content while having fun with the game. Therefore, it can be claimed that the teaching method using digital games [10] can improve students' learning skills and increase their academic achievement

Since so many types of games are available, suitable game-play must be identified before designing an entire game for students who have to learn the theoretical component of the OSI model. The key performance indicators for suitable game-play in this topic include enhancing student enjoyment [1],[11] and fun [4], reducing student stress [9], encouraging students' attention in learning difficulties [1], and contributing to the learning experience by helping their colleagues[1]. Therefore, the purpose of this study is not only to design and develop an academic game for teaching the OSI model, named Packet Warriors, but also to uncovers the suitable type of games for this context. The target group of this study is undergraduate students majoring in information sciences. 


\section{Objective}

- To disclose the suitable game type for teaching the OSI model in the undergraduate students majoring in information sciences.

- To design and develop an academic gaming application based on an OSI model, 'Packet Warriors', for smartphones.

- To compare the academic achievement for students before and after learning with the game.

- To study student satisfaction after learning with the game.

\section{Research Framework}

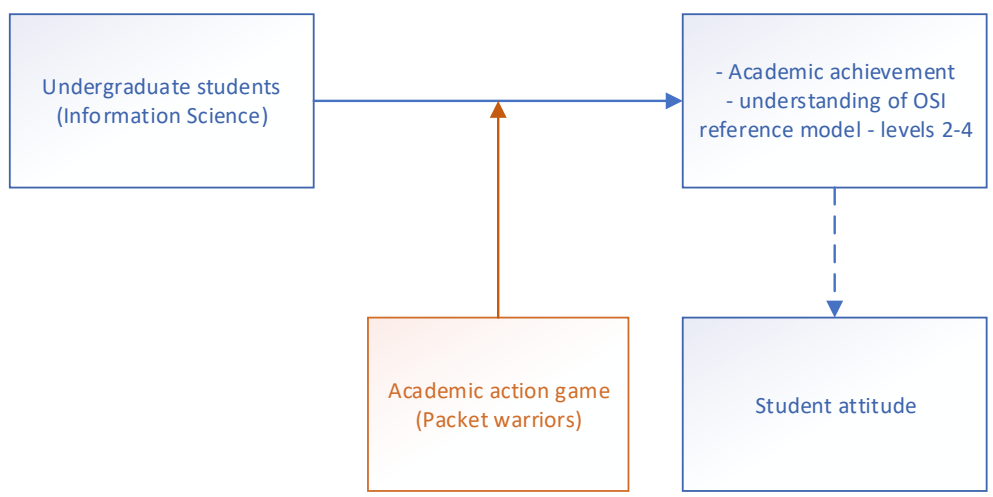

Fig. 1. The conceptual model for learning with the game

Accordingly, Fig. 1, the conceptual model of this study, shows that the main target of this study is undergraduate students majoring in information sciences. Additionally, the objective of this study is the academic achievement of students that can be measured by their game scores in each game level. Moreover, another outcome that can be obtained is the positive attitude of students who learn by playing this game. Thus, the stimulus in this experiment is the academic action game, "Packet Warriors".

To obtain the objective mentioned in the research framework above, the suitable research methodology is planned and managed. The details of this research method follow below.

\section{$4 \quad$ Research Methodology}

\subsection{Experimental design}

In this study, an experiment was conducted on third-year undergraduate students, majoring in information sciences, at Suan Sunandha Rajabhat University. This experiment aims to evaluate the learners' attitudes, including their academic achievement, 
toward the OSI model, which is a part of the information communication and networking course.

Before setting the specific game type for this topic, a survey was conducted by distributing a questionnaire to a sample group of 1,017 students enrolled in Suan Sunandha Rajabhat University. The objective of the questionnaire was to identify the students' appreciation of games based on generation. As a result, the outcome reports that the action game is the most popular among traditional undergraduate students. Thus, the game in this experiment was implemented as an action game.

As mentioned previously, undergraduate students love action games more than others. Therefore, this game was designed as an action game called Packet Warriors, with the role of every learner being a character on a virtual planet. Since the experiment is designed to measure the knowledge and impact of the game for 3 layers pf the OSI reference model, the contents in the game are separated into three chapters: "Data-link Layer", "Network Layer", and "Transport Layer".

This experiment consists of 5 steps. In the first step, students are administered a pretest. Second, the game is introduced to them in a computer lab. Third, students are administered a posttest. Fourth, questionnaires are given to the students for inquiry of satisfaction after using the application. Lastly, data are analyzed to check for the effectiveness of learning with the game.

\subsection{Participants}

To determine the objectives of this research, 19 participants, all of whom are thirdyear undergraduate students in the field of information studies, with the average age of 20 years old, are sampled. These samples consist of 9 males and 10 females; none of them has been enrolled in OSI courses or has a background in the OSI reference model. Additionally, the game is introduced to students in the computer lab as the control environment of this experiment. Therefore, there is no external influencer towards samples until the experiment is terminated.

\subsection{Materials}

There are three materials necessary for this experiment: a Packet warriors game application, academic achievement tests, and a student satisfaction questionnaire. Details of each component are described below.

Packet Warriors Game application: The objective of the game is to explain mechanisms within each layer while students concentrate on mechanisms, as well as floating data along these mechanisms, to win the game. In this process, the student's understanding of the concepts of the OSI reference model can be developed with enjoyment.

The design and development of this game is a digital game that consists of various elements [10], which are fun, gameplay, rules, goals, interactive, adaptive, outcomes, feedback, challenge, problem solving, interaction, representation and story [2],[13],[14]. Details of these elements are elaborated in Table 1, and Table 2 shows some main screens of the game. 
Table 1. Game elements in the Packet Warriors game

\begin{tabular}{|c|c|c|}
\hline Game element & Question & $\begin{array}{c}\text { Objective of } \\
\text { measurement }\end{array}$ \\
\hline Fun & Is the game fun to play? & \multirow{11}{*}{\begin{tabular}{|} 
To study the \\
degree of satis- \\
faction of \\
students who \\
have learned the \\
OSI model \\
through the \\
developed \\
game.
\end{tabular}} \\
\hline Gameplay & $\begin{array}{l}\text { Can playing games lead to positive effects regarding study } \\
\text { performance? }\end{array}$ & \\
\hline Rules & Are in-game instructions easy to understand? & \\
\hline Goals & $\begin{array}{l}\text { Can playing games help players to revise their previous } \\
\text { knowledge better than the traditional way of teaching? }\end{array}$ & \\
\hline Interactive & Is the in-game illustration beautiful, attractive and interesting? & \\
\hline Adaptive & $\begin{array}{l}\text { Can the players apply the knowledge from the game in their } \\
\text { daily life? }\end{array}$ & \\
\hline Outcomes and feedback & Can playing games help the players to study better? & \\
\hline Challenge & Is the game level suitable for players' ability? & \\
\hline Problem solving & Can playing games help solving problems in studies? & \\
\hline Interaction & $\begin{array}{l}\text { Can playing games help establishing cordial interaction among } \\
\text { friends? }\end{array}$ & \\
\hline Representation and story & Is the in-game narration interesting and suitable? & \\
\hline
\end{tabular}

Table 2. Table 2. Description of Packet Warriors

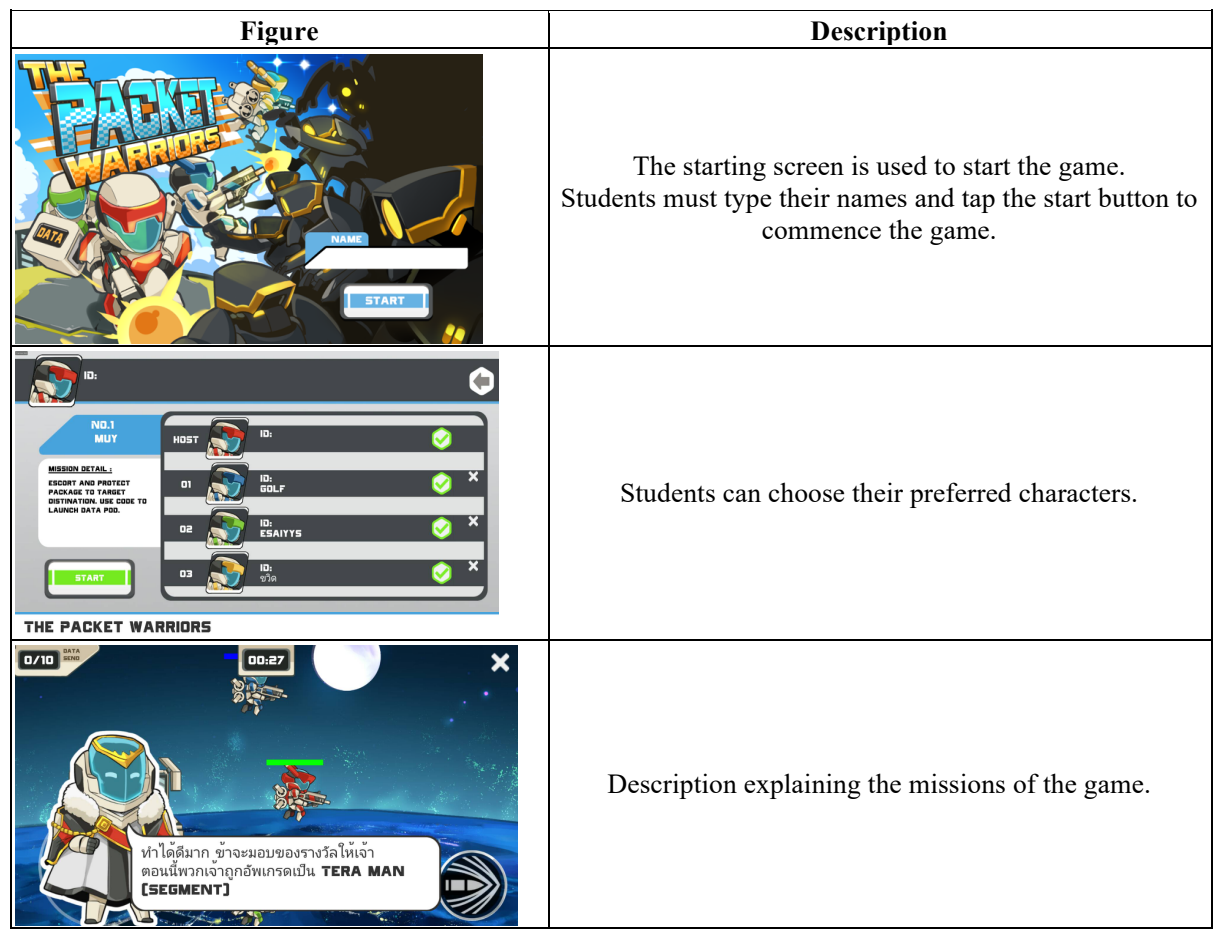




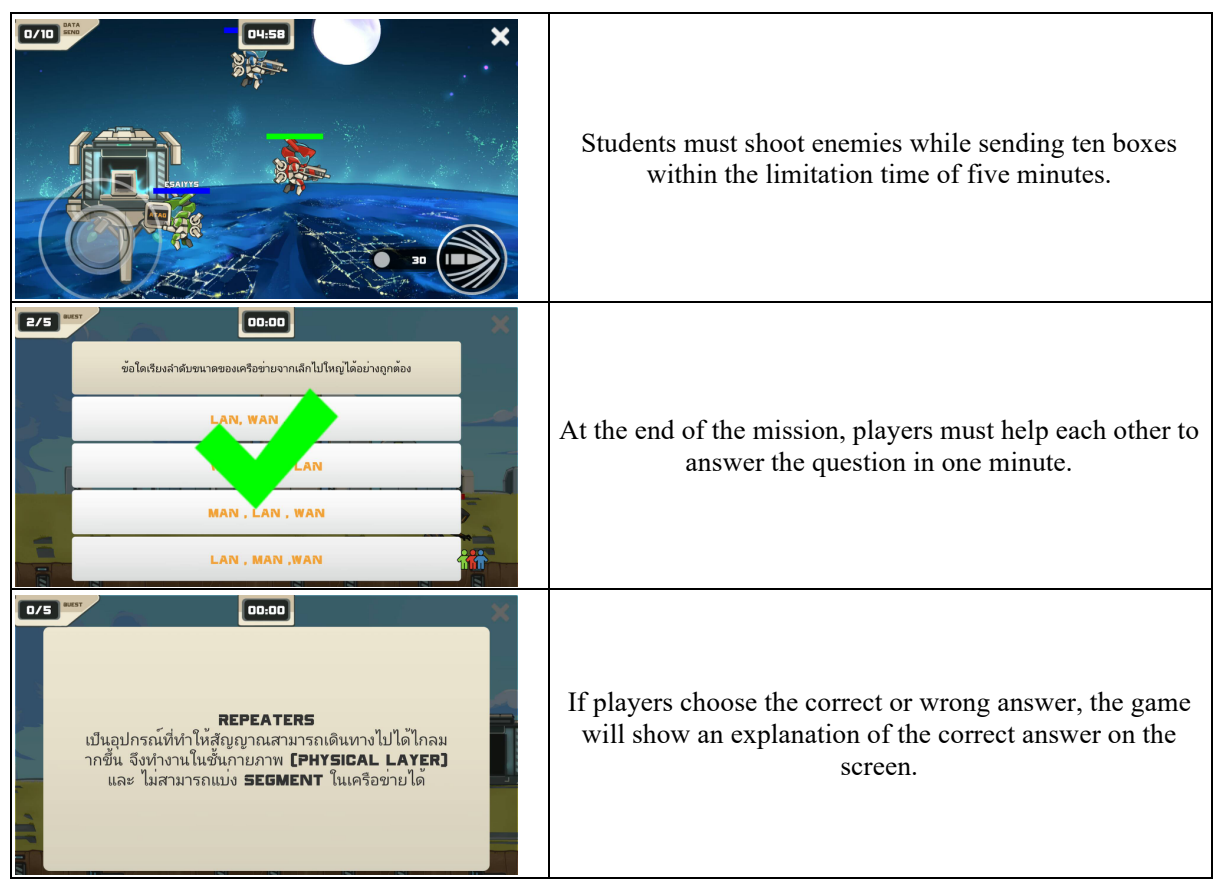

Contents in the game are as follows.

Chapter 1: Data link layer

- Ethernet

- Protocols and services in datalink layer

- Error checking and control

Chapter 2: Network layer

- Protocols and services in network layer

- Host to host

Chapter 3: Transport layer

- Protocols and services in transport layer

- Protocols and services provided by the application layer in the OSI model

- Process to process

- Encapsulation process

Academic achievement tests: There are two testing forms in this experiment: a pretest and a posttest. The purpose of the pretest exam is to measure students' knowledge, while the posttest exam aims to measure the success of the learning outcomes after playing the game.

Student satisfaction questionnaire: Since the game is developed for students' self-learning, the attraction from the game must be measured using the satisfaction 
index from students. The satisfaction score is a Likert scale with 5 levels, ranging from 1 to 5 .

\section{$5 \quad$ Findings}

The academic achievement test is based on the pretest and the posttest to compare the students' understanding before and after learning the given game [13]. The null hypothesis for the achievement is "There is no significant difference between the mean score of the pretest and the mean score of the posttest". Moreover, the analysis to answer this hypothesis is the paired $t$-test with a $95 \%$ confidence level. All descriptive values of this elicitation are shown in Table 3.

Table 3. Differences of scores between the pretest and the posttest

\begin{tabular}{|c|c|c|c|}
\hline Student & $\begin{array}{c}\text { Pretest } \\
(\%)\end{array}$ & $\begin{array}{c}\text { Posttest } \\
(\%)\end{array}$ & $\begin{array}{c}\text { Differences } \\
\text { (Posttest) - (Pretest) } \\
(\%)\end{array}$ \\
\hline 1 & 36.17 & 51.06 & 14.89 \\
\hline 2 & 25.53 & 76.60 & 51.07 \\
\hline 3 & 38.30 & 89.36 & 51.06 \\
\hline 4 & 44.68 & 76.60 & 31.92 \\
\hline 5 & 42.55 & 80.85 & 38.30 \\
\hline 6 & 44.68 & 65.96 & 21.28 \\
\hline 7 & 34.04 & 85.11 & 51.07 \\
\hline 8 & 17.02 & 63.83 & 46.81 \\
\hline 9 & 36.17 & 74.47 & 38.30 \\
\hline 10 & 31.91 & 61.70 & 29.79 \\
\hline 11 & 21.28 & 70.21 & 48.93 \\
\hline 12 & 31.91 & 63.83 & 31.92 \\
\hline 13 & 19.15 & 72.34 & 53.19 \\
\hline 14 & 29.79 & 68.09 & 38.30 \\
\hline 15 & 23.40 & 61.70 & 38.30 \\
\hline 16 & 27.66 & 78.72 & 51.06 \\
\hline 17 & 19.15 & 82.98 & 63.83 \\
\hline 18 & 40.43 & 82.98 & 42.55 \\
\hline 19 & 29.79 & 55.32 & 25.53 \\
\hline
\end{tabular}

The pretest and posttest results indicate that the posttest scores increased after playing "Packet Warriors", with a mean value of $71.67 \%$, which is higher than the pretest's mean value, $31.24 \%$. The largest difference in score is $63.83 \%$. In addition, 14.89 is the smallest difference in score.

To test the effectiveness of learning with the game, the paired samples $t$-test is applied. The results are presented in Table 4.

Table 4. Paired samples t-test of posttest - pretest data

\begin{tabular}{|l|c|c|c|c|c|}
\hline & Number $(\mathbf{N})$ & Mean $(\overline{\boldsymbol{x}})$ & S.D. & $\boldsymbol{t}$ & Sig. \\
\hline Post - Pre & 19 & 40.42 & 12.46 & 14.135 & .000 \\
\hline
\end{tabular}


The $t$-test shows that the differences of means from both tests are highly significant $(\mathrm{p}<0.05)$. Thus, these differences indicate that students can improve their learning skill and increase their achievements after playing the "Packet Warriors" game. Therefore, we can claim that the students' achievement can be achieved when they play suitable games.

Table 5. Student satisfaction after learning with the "Packet Warriors" game

\begin{tabular}{|c|l|c|c|}
\hline No & \multicolumn{1}{|c|}{ Question } & Mean & S.D. \\
\hline 1 & Is the game fun to play? & 4.21 & 0.78 \\
\hline 2 & Can playing games lead to the positive effects regarding study performance? & 4.47 & 0.51 \\
\hline 3 & Are in-game instructions easy to understand? & 4.05 & 0.62 \\
\hline 4 & $\begin{array}{l}\text { Can playing games help players to revise their previous knowledge better } \\
\text { than the normal way of teaching? }\end{array}$ & 4.58 & 0.69 \\
\hline 5 & Is the in-game illustration beautiful, attractive and interesting? & 4.16 & 0.60 \\
\hline 6 & Can the player apply the knowledge from the game in their daily life? & 4.16 & 0.50 \\
\hline 7 & Can playing games help the players to study better? & 4.47 & 0.69 \\
\hline 8 & Is the game level suitable for the player's ability? & 4.16 & 0.68 \\
\hline 9 & Can playing games help solving problems in studies? & 4.42 & 0.60 \\
\hline 10 & Can playing games help establishing cordial interaction among friends? & 4.37 & 0.76 \\
\hline 11 & Is the in-game narration interesting and suitable? & 4.21 & 0.71 \\
\hline
\end{tabular}

Table 5 shows relationships between the improvement of students' knowledge and their leaning skill with better problem-solving since the means of these three indicators are closely high to each other. In addition, the students' relationships are closer since the game is fun and the narrative of the game is interesting. Thus, Packet Warriors is able to help students to learn while having fun, helping them pay more attention in the learning process [14],[15],[16],[17]. Consequently, these results are consistent with the collected data that students have positive attitudes towards the learning by games. Fig. 2 demonstrates the relationships among factors mentioned in Table 5 .

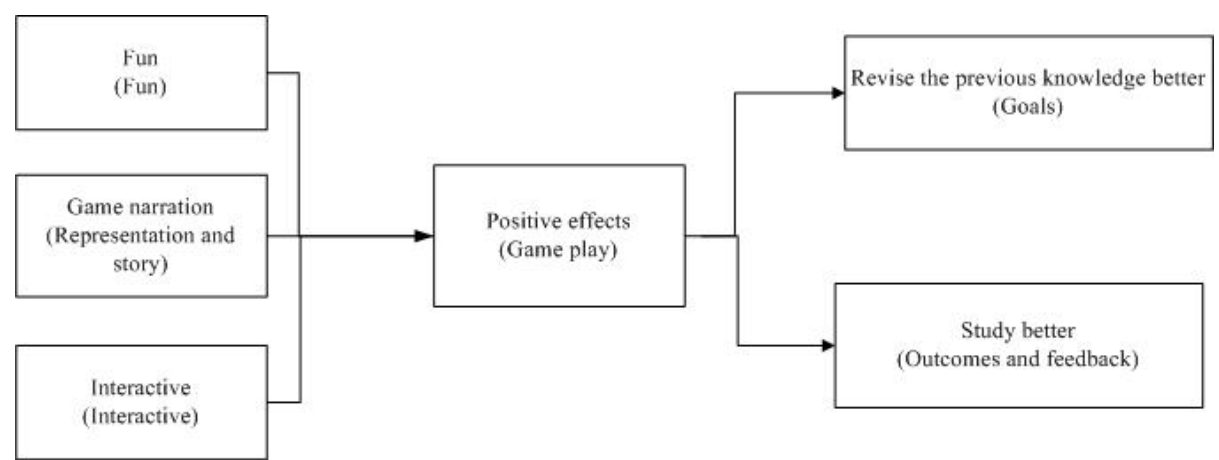

Fig. 2. Relationships among factors in Table 5. 


\section{Discussion}

According the literature, not all types of games are suitable for every learning context. Some games may be time consuming [3], while some games can be useful only to small groups of learners [3][5]. Moreover, some games only present the conceptual activities without providing the theoretical knowledge [8]. This research aims to unlock the time-consuming problem, the small-group problem and the difficultyto- explain theoretical concepts that cannot be conveyed by any other games.

To achieve the objective of this research, to develop a game to teach students in the theoretical part of the OSI reference model, an action game called "Packet Warrior" was designed, developed and evaluated. In the design process, to prevent students' stress and boredom, students generally pass each level within 5 minutes so that the time-consuming problem is solved. In addition, this game allows multiple players to simultaneously play the same game or play as a group with $\mathrm{n}$ players. Thus, the smallgroup problem is also solved.

The target sample group is students in the third year of undergraduate study majoring in information sciences, at Suan Sunandha Rajabhat University. The out-come of this research is the students' academic achievement when they learn the data communication subject through the Packet Warrior game, especially in the theoretical part of the OSI reference model. Thus, this game is practical and suitable for theoretical content of computer networking subject. Moreover, the relationships among students' achievement factors are consistent and obviously be seen. Therefore, the proposed platform can support students' learning skills and push the students' interest in the theoretical parts of the OSI reference model as expected.

\section{Conclusions}

This research aims to develop a game to teach the theoretical concepts of the OSI reference model to students who must learn data communication and net-working as a compulsory or an elective subject. In the beginning, the survey questionnaire was administered to most students at Suan Sunandha Rajabhat University to determine a suitable game for students of this generation. The result showed that the action game is the most popular game for them. Then, the script of the OSI reference model were was drawn based on the theoretical contents and the software design, and implementation was performed. After finishing this development process, 19 students in the thirdyear of undergraduate study majoring in information sciences, at Suan Sunandha Rajabhat University tested this system. The evaluation process was performed using the pretest and posttest data analyzed by a paired samples t-test at a $95 \%$ confident level. The result of this study shows that the action game "Packet Warrior" is an efficient tool for students to improve their learning capabilities through fun and good relationships with friends. 


\section{$8 \quad$ References}

[1] Begg, M., Dewhurst, D., \& Macleod, H. (2005). Game-informed learning: Applying computer game processes to higher education. Innovate: Journal of Online Education, 1(6).

[2] Chou, Y. S., Hou, H. T., Yu, M. C., Lee, H. J., Wu, H. S., Yang, Y. T., \& Liao, Y. J. (2012). Running TommyC: Developing a Digital Adventure Game Based on Situated Learning to Promote Learners' Concepts of Earthquake Escape. In Digital game and intelligent toy enhanced learning (DIGITEL), 2012 IEEE fourth international conference on pp. 156-158. https://doi.org/10.1109/digitel.2012.44

[3] Curzon, P. (2013). cs4fn and computational thinking unplugged. 8th workshop in primary and secondary computing education, pp. 47-50. https://doi.org/10.1145/2532748.2611263

[4] Ebner, M., \& Holzinger, A. (2007). Successful implementation of user-centered game based learning in higher education: An example from civil engineering. Computers \& education, 49(3), 873-890. https://doi.org/10.1016/i.compedu.2005.11.026

[5] Feaster, Y., Ali, F., Zhai, J., \& Hallstrom, J. O. (2013). Serious toys II: teaching networks, protocols, and algorithms. 18th ACM conference on Innovation and technology in computer science education, pp 273-278. https://doi.org/10.1145/2462476.2462502

[6] Fotouhi-Ghazvini, F., Earnshaw, R., Robison, D., \& Excell, P. (2009). The MOBO City: A mobile game package for technical language learning. International Journal of Interactive Mobile Technologies (iJIM), 3(2), 19-24. https://doi:10.3991/ijim.v3i2.757. https://doi.org/10.3991/ijim.v3i2.757

[7] Fuxiang, G., Lan, Y., Yu, Y., Xiuli, C., \& Dongmei, Z. (2009). Research on the Teaching Method for Computer Network Course. In Computer Science-Technology and Applications, 2009. IFCSTA'09. International Forum, pp. 414-416. https://doi.org/10.1109/ifcsta.2009.223

[8] Jarman, S., \& Bell, T. (2014). A game to teach network communication reliability problems and solutions. 9th Workshop in Primary and Secondary Computing Education, pp. 43-49. https://doi.org/10.1145/2670757.2670773

[9] Kanthan, R., \& Senger, J. L. (2011). The impact of specially designed digital games-based learning in undergraduate pathology and medical education. Archives of pathology \& laboratory medicine, 135(1), 135-142. https://doi.org/10.1016/j.ypat.2011.08.024

[10] M. Prensky, Digital Game-Based Learning. McGraw-Hill Trade, 2001.

[11] Matthews, J. N. (2005). Hands-on approach to teaching computer networking using packet traces. In Proceedings of the 6th conference on Information technology education, pp. 361367 https://doi.org/10.1145/1095714.1095777

[12] Mayer, I., Warmelink, H., \& Bekebrede, G. (2013). Learning in a game-based virtual environment: a comparative evaluation in higher education. European Journal of Engineering Education, 38(1), 85-106. https://doi.org/10.1080/03043797.2012.742872

[13] Pratama, L. D., \& Setyaningrum, W. (2018). GBL in Math Problem Solving: Is it Effective?. International Journal of Interactive Mobile Technologies (iJIM), 12(6), 101-111. https://doi.org/10.3991/ijim.v12i6.8658. https://doi.org/10.3991/ijim.v12i6.8658

[14] Rashid, N. A. M., Salleh, S. M., \& Noor, N. M. (2018). The Role of Game Elements in Improving Jawi Skills through a Mobile Game'G-Jawi'. International Journal of Interactive Mobile Technologies (iJIM), 12(7): 20-30. https://doi.org/10.3991/ijim.v12i7.9636. https://doi.org/10.3991/ijim.v12i7.9636

[15] She, Y. X., Lin, M. H., Jong, B. S., \& Hsia, Y. T. (2013). Using Growing Pet Game in Facebook to Enhance Students' Learning Motivation: In Operating System Course. In Learning and Teaching in Computing and Engineering (LaTiCE), 2013, pp. 224-228. https://doi.org/10.1109/latice.2013.11 
[16] Sung, H. Y., \& Hwang, G. J. (2013). A collaborative game-based learning approach to improving students' learning performance in science courses. Computers \& Education, 63, 43-51. https://doi.org/10.1016/j.compedu.2012.11.019

[17] Wang, C. S., \& Li, Y. C. (2009, August). Integrated network management certification training with computer game: A knowledge placement framework. In INC, IMS and IDC, 2009. NCM'09. Fifth International Joint Conference, pp. 1842-1845. https://doi.org/10.1109/ncm.2009.141

[18] Zou, Y. (2011, December). Study on teaching reform of computer networks course. In IT in Medicine and Education (ITME), 2011 International Symposium, pp. 579-582.

\section{Authors}

Thanakorn Uiphanit is currently a Ph.D. student in the Technopreneurship and Innovation Management Program at the Chulalongkorn University, Bangkok 10330, Thailand. He also works at the Suan Sunandha Rajabhat University, Bangkok, Thailand. E-mail: thanakorn.u@student.chula.ac.th

Pattarasinee Bhattarakosol is currently an Assistance Professor in the Department of Mathematics and Computer Science, Faculty of Science, Chulalongkorn University, Bangkok 10330, Thailand. E-mail: pattarasinee.b@chula.ac.th

Kwanrat Suanpong is currently a Lecturer in the Department of Commerce, Chulalongkorn Business School, Chulalongkorn University, Bangkok 10330, Thailand. E-mail: kwanrats@cbs.chula.ac.th

Sompoch Iamsupasit is currently an Associate Professor in the Faculty of Psychology, Chulalongkorn University, Bangkok 10330, Thailand. E-mail: isompoch@hotmail.com

Article submitted 2019-03-12. Resubmitted 2019-04-04. Final acceptance 2019-04-04. Final version published as submitted by the authors. 